\title{
IDENTIFICATION OF FATTY ACIDS IN SACHA INCHI OIL (CURSIVE PLUKENETIA VOLUBILIS L.) FROM ECUADOR
}

\author{
CARRILLO W ${ }^{1,3 *}$, QUINTEROS M F ${ }^{1}$, CARPIO C ${ }^{1}$, MORALES D ${ }^{1}$,VÁSQUEZ G ${ }^{2}$,ÁLVAREZ M $^{1}$, SILVA M ${ }^{1}$
}

${ }^{1}$ Laboratory of Functional Foods, Faculty of Foods Science and Engineering, Technical University of Ambato. Av. Los Chasquis y Rio Payamino. Campus Huachi, CP 1801334, Ambato, Ecuador. ${ }^{2}$ Escuela Superior Politécnica del Litoral, ESPOL, Faculty of Mechanical Engineering and Production Sciences, Campus Gustavo Galindo Km 30.5 VíaPerimetral, Guayaquil, Ecuador. ${ }^{3}$ Department of Research. Bolivar State University, Academic Campus, Alpacha EC. Av Ernesto Che Guevara s/n and Av Gabriel Secaira, EC 020150, Guaranda, Ecuador. Email: Wi.carrillo@uta.edu.ec

Received: 04 October 2016, Revised and Accepted: 10 October 2016

\section{ABSTRACT}

Objective: The aim of this study was to identify fatty acids in a sacha inchi oil sample.

Methods: Sacha inchi oil was obtained of sacha inchi seeds using the cold pressing method. Fatty acids analysis was carried out using the gas chromatography with a mass selective detector and using the database Library NIST14.L to identify the compounds.

Results: Sacha inchi seeds have a high content of unsaturated fatty acids with $34.98 \%$ of $๑ 6 \alpha$ - Linoleic and $47.04 \%$ of $₫ 3 \alpha$ - Linolenic. Sacha inchi seeds only have $3.98 \%$ of palmitic acid.

Conclusions: Sacha inchi seed is a good source of fatty acids $₫ 3$ and $\odot 6$, being $\odot 3$ and $\bowtie 6$ in a good proportion. Sacha inchi oil can be used to elaborate functional foods.

Keywords: Sacha inchi, Pluketeniavolubilis, Fatty acids, Gas chromatography - mass selective detector, Methyl ester.

(C) 2018 The Authors. Published by Innovare Academic Sciences Pvt Ltd. This is an open access article under the CC BY license (http://creativecommons. org/licenses/by/4. 0/) DOI: http://dx.doi.org/10.22159/ajpcr.2018.v11i2.15515

\section{INTRODUCTION}

Sacha inchi (Pluketeniavolubilis L), also named Inca peanut, is a plant that grows in the wild being native of the rainforests in the Andean region of South America. This plant belongs to the Euphorbiaceae family and is composed of nineteen species [1]. It is known that sacha inchi seeds have a high content of oil (35-60\%) and proteins $(27 \%)$ and contain heat-labile substances with a bitter taste [2].

Different studies have reported unsaturated fatty acids in sacha inchi seeds, being around $93 \%$ unsaturated fatty acids of the total fatty acids. In particular, high levels of essential fatty acids (EFA) were found, namely, C18:3 $\omega 3(\alpha-\mathrm{Ln}$, cis, cis,cis-9,12,15-octadecatrienoic acid; $\alpha$-linolenic) and C18:2 $\omega 6$ (L, cis,cis-9,12-octadecadienoic acid; $\alpha$-linoleic) fatty acids, accounting approximately of $47 \%$ and $37 \%$, respectively, of the total fatty acids $[3,4]$. EFAs are intermediate metabolite in the synthesis of some many compounds in the human organism, such as prostaglandin E1 and its derivate. Several studies have reported that $\omega-6$, and especially, $\omega$ - 3 unsaturated fatty acids have beneficial effects on human health by preventing several diseases such as cancer, coronary heart disease, and hypertension $[5,6]$. The aim of this work was to characterize the composition of fatty acids methyl esters (FAMEs) present in sacha inchi oil samples cultivated in Ecuador by gas chromatography-mass selective detector (GC-MSD). The knowledge acquired in this study will help to determine the potential of sacha inchi seed oil to be commercially exploited for industrial applications and incorporation into functional foods to help human health.

\section{METHODS}

\section{Oil extraction}

Sacha inchi was cultivated in Amazon Ecuadorian. Sacha inchi oil sample was obtained using the cold pressed method from sacha inchi seeds. Oil was then stored at $4.0 \pm 2{ }^{\circ} \mathrm{C}$. Oil extraction was conducted using a Soxhlet apparatus during approximately $5 \mathrm{~h}$ with hexane as solvent, with a solid-to-solvent ratio of $1 / 7 \mathrm{~m} / \mathrm{v}$. After the extraction process, the flask contents were filtered, and the liquid fraction containing the lipid extract and solvent was poured into a 250 -mL flask of a rotary film evaporator to remove the solvent. The obtained oil was collected, evaporated under nitrogen, weighed, and stored in sealed amber glass vials at $-20^{\circ} \mathrm{C}$ until analysis [7].

Fatty acids analysis by GC-MSD

The fatty acid composition of oil extracted from sacha inchi seeds was analyzed by injecting FAMEs [8] into an Agilent Technologies 7980Asystem GC (Agilent, Santa Clara, CA) equipped with a MSD 5977A GC/MSD, an auto-sampler7693, column $(60 \mathrm{~m} \times 250 \mu \mathrm{m} \times 0.25 \mu \mathrm{m}$, Agilent 122-7062). The oven temperature was programed as follows: From $80^{\circ} \mathrm{C}$, ramp 1: To $100^{\circ} \mathrm{C}$ at $20^{\circ} \mathrm{C} / \mathrm{min}$ during $1 \mathrm{~min}$; ramp 2: At $200^{\circ} \mathrm{C}$ at $25^{\circ} \mathrm{C} / \mathrm{min}$ during $10 \mathrm{~min}$; and ramp 3: At $250^{\circ} \mathrm{C}$ at $2^{\circ} \mathrm{C} / \mathrm{min}$. The injector and detector temperatures were set at $250^{\circ} \mathrm{C}$. Helium was used as carrier gas at a linear flow velocity of $1.4 \mathrm{~mL} / \mathrm{min}$.

\section{RESULTS}

Sacha inchi fruits either in immature or mature state have a four-point, five-point, and six-point stars, respectively, with a seed inside each start point (Fig. 1a and b). It is then necessary to remove the skin of the fruit before obtaining the sacha inchi oil (Fig. 1c and d).

Sacha inchi oil sample was obtained with cold pressing method, and fatty acids were subsequently methyl esterified. Fatty acids from sacha inchi were identified using GC/MSD. The precursor ions were compared to three database Library NIST14. L. Five majority peaks were identified with their associated retention time: $\mathrm{C} 16: 0$ with a retention time of $19.332 \mathrm{~min}$; C18:0 with a retention time of $26.005 \mathrm{~min}$; C18:1c with a retention time of $26.869 \mathrm{~min}$; C18:2 with a retention time of $28.644 \mathrm{~min}$, and finally, C18:3 with a retention time of $31.122 \mathrm{~min}$ (Fig. 2).

The concentration of fatty acids was calculated with a peak area percentage. FAMEs were characterized as follows: C16:0 palmitic acid 
with $3.98 \%$ of fatty content, C18:0 stearic acid with $3.12 \%$ of fatty content, C18:1c oleic acid with $8.58 \%$ of fatty content, C18:2 linoleic acid (LA) with $34.98 \%$ of fatty content, and finally, C18:3 linolenic acid with $47.04 \%$ of fatty content (Table 1 ).

When the sacha inchi fatty acid composition is compared with some common vegetable oils, it can be seen that only olive oil has a high content of mono-unsaturated fatty acids, and C18:1 named oleic acid with $77.6 \%$ of oleic acid. Sacha inchi oil has only a content of $8.58 \%$ of oleic acid. Sacha inchi has a high content of polyunsaturated fatty

Table 1: FAMEs identified in sacha inchi oil sample from Ecuador by GC/MSD analysis together with their peak area ratio percentage

\begin{tabular}{|c|c|c|c|}
\hline Peak & $\begin{array}{l}\text { Peak area } \\
\text { ratio }(\%)\end{array}$ & $\begin{array}{l}\text { Carbon number: Double } \\
\text { bound }\end{array}$ & FAMEs name \\
\hline 19.332 & 3.98 & C16:0 & Palmitic acid \\
\hline 26.005 & 3.12 & C18:0 & Stearic acid \\
\hline $\begin{array}{l}26.869 \\
28.644\end{array}$ & $\begin{array}{l}8.58 \\
34.98\end{array}$ & $\begin{array}{l}\text { A9 - C18:1c } \\
\text { A9,12- C18:2 }\end{array}$ & $\begin{array}{l}\text { Oleic acid } \\
\text { Linoleic acid }\end{array}$ \\
\hline 31.122 & 47.04 & A9,12,15- C18:3 & $\begin{array}{l}\text { Linolenic } \\
\text { acid }\end{array}$ \\
\hline
\end{tabular}

GC/MSD: Gas chromatography/mass selective detector, FAMEs: Fatty acids methyl esters

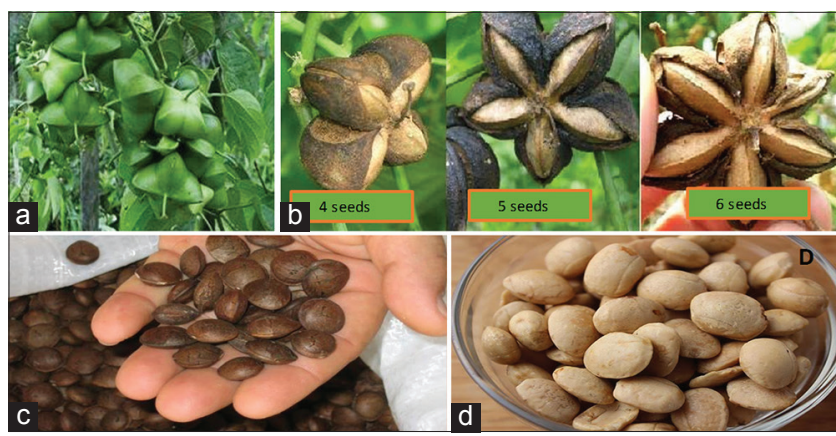

Fig. 1: (a) Sacha inchi green fruit (b) Sacha inchi seed mature (c) Sacha inchi seed mature with peel (d) Sacha inchi without peel. acids (PUFAs). Olive oil contains few omega- 6 and omega-3 fatty acids with $9.0 \%$ and $1.0 \%$, respectively (Table 2). Oleic acid is recommended as an intake of monounsaturated fatty acids to reduce the risk of cardiovascular diseases.

On the other hand, sacha oil contains a high content of omega 6 and omega 3 fatty acids. The optimum ratio of those two fatty acids, omega 6 and omega 3 is $1: 1$ and $4: 1$ [10]. The ratio found in sacha inchi oil of omega 6:omega 3 is $1: 1.3$.

Many of the chronic conditions, cardiovascular diseases, diabetes, cancer, obesity, autoimmune diseases, rheumatoid arthritis, asthma, and depression are associated with an increased production of thromboxane A2, leukotriene B4 (LTB4), interleukin (IL) $-1 \alpha$, IL-6, tumor necrosis factor (TNF), and C-reactive protein. The previous molecule levels increase with increases in omega- 6 fatty acid intakes and decrease with increases in omega- 3 fatty acid intakes [11,12]. Sacha inchi oil contains more omega-3 in its composition. Therefore, sacha inchi can be a good candidate to prevent different diseases such as cancer, cardiovascular diseases, diabetes, and others.

\section{DISCUSSION}

Lipids are a major component of the human diet. EFAs are crucial dietary constituents for normal growth, development, and maintenance of internal homeostasis. High quantities of EFA may be found in plant seeds distributed in many regions of the world. These plants can provide oils with a high concentration of monounsaturated fatty acids that prevent cardiovascular diseases through several mechanisms [13]. The consumption of saturated fat in Ecuador is high, and the balance 3 and $₫ 6$ is not correct in many processed foods. Dietary EFA includes LA, an n-6 FA, and alpha-linolenic acid (ALA), an n-3 FA. These EFA cannot be synthesized by the human body being necessary to supply them through dietary intake [14-16]. More importantly, EFA is metabolized with very long-chains (VLC) PUFAs. For instance, LA is converted to VLCPUFA arachidonic acid, and ALA is converted to both VLCPUFAs eicosapentaenoic acid and docosahexaenoic acid. Both EFA and their associated VLCPUFA metabolites are important for various body functions, including growth, immunity function, and cognitive development $[17,18]$

The results obtained in this study are in accordance to fatty acids levels from sacha inchi seeds reported in different studies. Fanali et al., 2011, has reported $36.2 \%$ of linolenic acid ( $\odot 6)$ and $46.8 \%$ of linoleic acid (๑3) [2]. Fanali et al. only reported $4.0 \%$ of palmitic acid content.

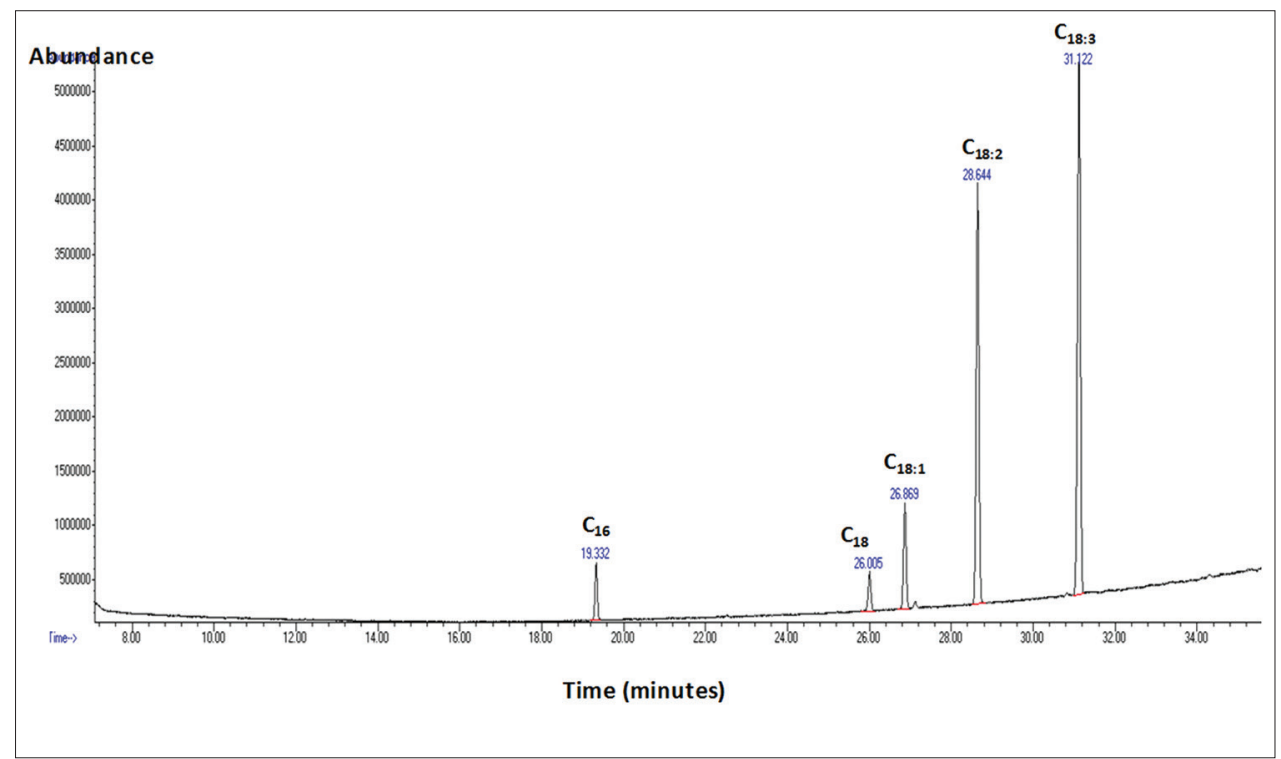

Fig. 2: Gas chromatography-mass selective detector analysis of fatty acids present in sacha inchi oil sample 
Table 2: Fatty acid composition (\%) of six vegetable oils

\begin{tabular}{|c|c|c|c|c|c|c|c|}
\hline Reference & Vegetal oil & C16:0 & C16:1 & C18:0 & C18:1 & C18:2 & C18:3 \\
\hline [9] & Olive oil & 13.8 & 1.4 & 2.8 & 71.6 & 9.0 & 1.0 \\
\hline [9] & Sunflower oil & 5.2 & 0.1 & 3.7 & 33.7 & 56.5 & 0.0 \\
\hline [9] & Palm oil & 44.8 & 0.0 & 4.6 & 38.9 & 9.5 & 0.4 \\
\hline [9] & Soybean oil & 10.1 & 0.0 & 4.3 & 22.3 & 53.7 & 8.1 \\
\hline \multirow[t]{2}{*}{ [9] } & Corn oil & 11.6 & 0.0 & 2.5 & 38.7 & 44.7 & 1.4 \\
\hline & Sacha inchi oil & 3.98 & 0.0 & 3.12 & 8.58 & 34.98 & 47.04 \\
\hline
\end{tabular}

Gutiérrez et al., 2011, reported 33.4\% of linolenic acid (Ф6), 50.8\% of linoleic acid ( $\odot 3)$, and $4.4 \%$ of palmitic acid [19]. Bondioli and Bella, 2006 , reported $33.67 \%$ of linolenic acid (๑6), 50.73\% of linoleic acid (๑3), and $3.79 \%$ of palmitic acid [20]. Sacha inchi oil can be a good alternative in Ecuador to be used in the food industry due to its high nutritional quality.

\section{ACKNOWLEDGMENTS}

This study was supported by Universidad Técnica de Ambato, Ecuador (Project CPU-1373-2014-UTA) and (Project Canje de DeudaEspañaEcuador). This work has been reviewed in the English edition by Emilio Labrador. Carrillo W thanks to Abraham Sánchez to supply sacha inchi seeds.

\section{AUTHOR CONTRIBUTIONS}

Quinteros MF, Carpio C, Morales D, Vasquez G and Carrillo W conceived and designed the experiments. Silva $M$ and Alvarez $M$ performed the gas chromatography analyses. Carrillo W wrote the paper.

\section{CONFLICT OF INTERESTS}

The authors declare no conflict of interest.

\section{REFERENCES}

1. Sathe SK, Kshirsagar HH, Sharma GM. Solubilization, fractionation, and electrophoretic characterization of inca peanut (Plukenetia volubilis L.) proteins. Plant Foods Hum Nutr 2012;67:247-55.

2. Fanali C, Dugo L, Cacciola F, Beccaria M, Grasso S, Dachà M, et al. Chemical characterization of sacha inchi (Plukenetia volubilis L.) oil. J Agric Food Chem 2011;59:13043-9.

3. Horrobin DF. The role of essential fatty acids and prostaglandins in the premenstrual syndrome. J Reprod Med 1983;28:465-8.

4. Burdge GC, Calder PC. Conversion of alpha-linolenic acid to longerchain polyunsaturated fatty acids in human adults. Reprod Nutr Dev 2005;45:581-97.

5. Roynette CE, Calder PC, Dupertuis YM, Pichard C. N-3 polyunsaturated fatty acids and colon cancer prevention. Clin Nutr 2004;23:139-51.

6. Siri-Tarino PW, Chiu S, Bergeron N, Krauss RM. Saturated fats versus polyunsaturated fats versus carbohydrates for cardiovascular disease prevention and treatment. Annu Rev Nutr 2015;35:517-43.

7. Theresia JJ, Austin PC, Kelly V, Mary A, Wei L, Joyce LK, et al. Evaluation of fattyacid and mineral content of Tanzanian seeds and oils. J Food Comp Anal 2016;50:108-13.

8. Carrillo W, Carpio C, Morales D, Vilcacundo E, Alvarez M, Silva M.
Content of fatty acids in corn (Zea mays L.) oil from Ecuador. Asian J Pharm Clin Res 2017;10:150-3.

9. Kamal-Eldin A, Andersson R. A multivariate study of the correlation between tocopherolcontent and fatty acid composition in vegetable oils. J Am Oil Chem Soc 1997;4:375-80.

10. Simopoulos AP. The importance of the ratio of omega-6/omega-3 essential fatty acids. Biomed Pharmacother 2002;56:365-79.

11. Weber PC, Leaf A. Cardiovascular effects of w3 fatty acids: Atherosclerotic risk factor modification by w3 fatty acids. World Rev Nutr Diet 1991;66:218-32.

12. Simopoulos AP. New products from the agri-food industry: The return of n-3 fatty acids into the food supply. Lipids 1999;34 Suppl: S297-301.

13. Lopez-Miranda J, Perez-Jimenez F, Ros E, De Caterina R, Badimon L, CovasMI, et al. Olive Oil and Health: Summary of The II International Conference on Olive Oil and Health Consensus Report, Jaen and Cordoba (Spain) 2008. Nutri Metabol Cardiovasc Dis NMCD 2010;20:284-94.

14. Huffman SL, Harika RK, Eilander A, Osendarp SJ. Essential fats: How do they affect growth and development of infants and young children in developing countries? A literature review. Matern Child Nutr 2011;7 Suppl 3:44-65.

15. Kuipers RS, Luxwolda MF, Sango WS, Kwesigabo G, DijckBrouwer DA, Muskiet FA, et al. Postdelivery changes in maternal and infant erythrocyte fatty acids in 3 populations differing in fresh water fish intakes. Prostaglandins Leukot Essent Fatty Acids 2011;85:387-97

16. Luxwolda MF, Kuipers RS, Koops JH, Muller S, de Graaf D, DijckBrouwer DA, et al. Interrelationships between maternal DHA in erythrocytes, milk and adipose tissue. Is $1 \mathrm{wt} \%$ DHA the optimal human milk content? Data from four tanzanian tribes differing in lifetime stable intakes of fish. Br J Nutr 2014;111:854-66.

17. Ackatia-Armah RS, McDonald CM, Doumbia S, Erhardt JG, Hamer DH, Brown KH, et al. Malian children with moderate acute malnutrition who are treated with lipid-based dietary supplements have greater weight gains and recovery rates than those treated with locally produced cereal-legume products: A community-based, clusterrandomized trial. Am J Clin Nutr 2015;101:632-45.

18. Michaelsen KF, Dewey KG, Perez-Exposito AB, Nurhasan M, Lauritzen L, Roos N, et al. Food sources and intake of n-6 and n-3 fatty acids in low-income countries with emphasis on infants, young children (6-24 months), and pregnant and lactating women. Matern Child Nutr 2011;7 Suppl 2:124-40.

19. Gutiérrez LF, Rosada LM, Jiménez A. Chemical composition of Sacha Inchi (Plukenetiavolubilis L.) seeds and characteristics of their lipid fraction. Grasas Aceites 2011;62:76-83.

20. Bondioli P, Bella LD. Alpha linolenic acid rich oils. Composition of Plukenetiavolubilis (Sacha Inchi) oil from Perú. Riv Ital Sostanze Grasse 2006;53:120-3. 